DOI: $10.21802 / \operatorname{artm} .2020 .3 .15 .198$.

УДК 37.091 .2

\title{
ТЕХНІЧНІ АСПЕКТИ СТВОРЕННЯ ОНЛАЙН-КУРСІВ НА ПЛАТФОРМІ ОРЕN ДЛЯ ЗМІШАНОГО НАВЧАННЯ
}

\author{
I.M. Поясник
}

Івано-Франківський начіональний медичний університет, кафедра неврологї та нейрохірургї, м. Івано-Франківськ, Украӥна, ORCID ID: 0000-0002-6965-8631, e-mail:sof.3425@gmail.com

Резюме. Нова концепція розвитку вищої медичної освіти в Україні, що орієнтується на світові досягнення підготовки лікарів, передбачає корінні зміни якості освіти. Онлайн-курси мають безліч переваг порівняно 3 традиційним навчанням в університеті. Аналіз навчального плану і програм навчальних дисциплін системи медичної освіти показав, що саме “онлайн-курси”, з позицій організації навчального процесу та дидактики викладання, найбільш адаптовані до комбінованої або дистанційної форми навчання.

Мета: створити й розробити онлайн-курс на платформі Open edX для мотивованих лікарів, науковопедагогічних працівників, яким необхідні знання для професійного розвитку, підвищення кваліфікації або перекваліфікації.

Матеріали та методи. Платформа Open edX нова, з відкритим вихідним кодом, що створює студентам і педагогам нові можливості творити й ділитися, викладати й вивчати через дослідження; адаптуватися до індивідуальних навчальних потреб. Вона використовується для дистанційного навчання в будь-який час і в будьякому місці, з вільним графіком навчання (у межах періоду проходження курсу).

Результати. Після затверждення робочої програми члени команди приступають до розробки проекту сценарію онлайн-курсу. Наступний етап - створення сценарію онлайн-курсу. Це завершений проект, який розпочинає новий етап - технічне заповнення матеріалом онлайн-курсу на платформу Open edX Studio, після якого відбувається бета-тестування.

Висновки. Дистанційне навчання може бути таким же ефективним, як і традиційне. Масові відкриті онлайн-курси в інтернеті активно витісняють інші форми дистанційного навчання. Залучення в навчальний процес альтернативних методів навчання та знання їх створення є актуальним.

Ключові слова: дистанційна освіта, онлайн-курс, платформа Open edX.

Вступ. Нова концепція розвитку вищої медичної освіти в Україні, що орієнтується на світові досягнення підготовки лікарів, передбачає корінні зміни якості освіти. Необхідність іiі реформування й удосконалення є однією з вимог на шляху до євроінтеграції. Рух до європейського освітнього простору передбачає ряд змін, що стосуються як навчальних предметів, так і методів їх викладання. Зростання актуальності якості медичної освіти пояснюється ще й тим, що вищі навчальні заклади отримали більше прав у виборі методів та змісту освіти [1].

Інновації - це новостворені чи вдосконалені конкурентноспроможні технології, що істотно поліпшують якість навчання та підвищують результативність праці. Незважаючи на те, що в медичних навчальних закладах традиційна освіта, безумовно, буде домінуючою і в основі своїй аудиторною, проте в даний час свою нішу займає і комбінована освіта -3 позааудиторним онлайн-навчанням, як $є$ відносно новою галуззю, що швидко розвивається. Міжкультурні навчальні середовища дають можливість обміну досвідом, спільного рішенням проблем, формування зв'язків з колегами по всьому світу $[1,11]$.

Стрімкий розвиток технологій дистанційного навчання та формування інфраструктури $3 \mathrm{G}$, активне використання мобільних пристроїв студентами ство- рюють умови для імплементації цих технологій у навчальний процес. Аналіз навчального плану і програм навчальних дисциплін системи медичної освіти показав, що саме “онлайн-курси”, 3 позицій організації навчального процесу та дидактики викладання, найбільш адаптовані до комбінованої або дистанційної форми навчання [2].

В Україні дистанційна форма навчання регламентована наказом МОН від 30.10.13 № 1518 “Про затвердження Вимог до вищих навчальних закладів та закладів післядипломної освіти, наукових, освітньо-наукових установ, що надають освітні послуги за дистанційною формою навчання $з$ підготовки та підвищення кваліфікації фахівців за акредитованими напрямами і спеціальностями" i наказом МОН від 25.04.13 № 466 "Про затвердження Положення про дистанційне навчання" [3].

Обгрунтування дослідження. Онлайн-курси мають безліч переваг порівняно з традиційним навчанням в університеті. Вони відкриті, тобто будьякий охочий може записатися на них. Вони дійсно масові: замість того щоб читати лекцію в аудиторії для 100 студентів, викладач читає іiї для студентів по всьому світу, географія студентів обмежена тільки можливістю доступу до інтернету. Крім того, подача матеріалу відбувається відразу декількома каналами, 
включаючи можливість інтерактивної взаємодії [4]. Платформа Open edX новіша, з відкритим вихідним кодом, що створює учням і педагогам нові можливості творити й ділитися, викладати й вивчати через дослідження; адаптуватися до індивідуальних навчальних потреб, щоб вони могли створювати, проектувати, винаходити й будувати за допомогою технологій [3]. Резерви глобального інноваційного освітнього середовища платформи створюють можливості університету переглянути спектр пропонованих освітніх послуг.

Мета: створити й розробити онлайн-курс на платформі Open edX для мотивованих лікарів, науково-педагогічних працівників, яким необхідні знання для професійного розвитку, підвищення кваліфікації або перекваліфікації.

Матеріали і методи. Уже кілька десятиліть в усьому світі активно розвивається концепція масового відкритого онлайн-курсу (від англ. МООС Massive Open Online Courses, масові відкриті онлайнкурси) як альтернатива дорогої і не завжди зручної системи традиційної освіти. Прикладів таких систем, які набрали популярність і певну кількість постійних користувачів (одна 3 головних ознак успішності MOOC), можна навести десятки [5]. Однією з них є платформа Open edX, заснована Гарвардським університетом і Массачусетським технологічним інститутом у 2012 році. На платформі Open edX на даний час розміщено понад 2000 курсів (1000 вступного характеру), 75 видають професійні сертифікати, домінуюча кількість курсів англійською мовою - від 130 партнерів [6]. Вона використовується для дистанційного навчання в будь-який час і в будь-якому місці. При цьому платформа Open edX новіша, 3 відкритим вихідним кодом, що створює учням і педагогам нові можливості творити й ділитися, викладати й вивчати через дослідження; адаптуватися до індивідуальних навчальних потреб, щоб вони могли створювати, проектувати, винаходити й будувати за допомогою технологій $[7,8]$. Ще однією перевагою є вільний графік навчання - кожен учасник може самостійно формувати свій графік навчання. Ви можете переглянути записаний відеоурок або зробити домашнє завдання в будь-який зручний для вас час, але в межах періоду проходження курсу. Ця концепція називається активним навчанням [5].

3 огляду на вищевикладені переваги Open edX, на кафедрі неврології та нейрохірургії було вибрано цю платформу для створення онлайн-курсів для тематичного удосконалення лікарів.

Результати дослідження та їх обговорення. Для створення МООС, зрозуміло, необхідна, поперше, ідея (з формуванням мети курсу, баченням цільової аудиторії, результатів навчання), планування кожного кроку в створенні (з підготовкою педагогічного сценарію, консультацією методиста, експертизою матеріалів курсу, формуванням команди курсу, складанням календарного плану) i правильна організація з початкової підготовкою кошторису [9].

Курс розробляють члени команди, всі з яких повинні мати облікові записи на платформі, при додаванні нового члена команди в розробку курсу вка- зується його e-mail. Studio - це веб-додаток, інструмент розробки і структурування курсу Open edX. Для доступу до інструментів розробки необхідно пройти реєстрацію на edge.edx.org або використовувати безкоштовну пробну версію Studio від постачальника в співтоваристві Open edX. При створенні першого або нового курсу необхідно вибрати кнопку "Your First Course" або "New Course" на панелі інструментів Studio Home, після чого вводиться інформація про новий курс (назва курсу, назва організації, абревіатура суб'єкта з номером курсу). У кожному полі є пояснення для заповнення форми. Ядром будь-якого курсу $€$ зміст на вкладці "Course", щоб додати вміст необхідно перейти на екран "Course Outline", де деталізувати розділи, підрозділи і блоки (кожен блок відображається як одна сторінка). У розділі «Course Outline» використовуйте кнопки «+ New Section», «+ New Subsections» i «+ New Units», щоб створити ієрархію вмісту. Щоб редагувати установки і видалити елементи курсу користуються кнопками «Налаштування» і «Кошик». Змінити порядок вмісту можна перетягуючи розділи, підрозділи або юніти. Для перегляду відображення курсу очима студентів існує кнопка "View Live". У Розділі "Course Schedule" вказуються дати початку та завершення реєстрації на курс, закінчення курсу [6].

Компоненти - це контент (відео, текст в HTML, теми для обговорень, тести в XML), які додаються опцією "Add a New Component". $€$ шаблони HTML-тексту. При копіюванні тексту, фіксованого у вікно редагування, він може відображатися без вихідного формату, для чого необхідна його корекція, краще копіювати невідформатований текст. Чорновий режим додавання контенту відзначається жовтою смугою вздовж підрозділу. Контент має налаштування на дату випуску для студентів. При додаванні компонента обговорення заповнюється поле теми обговорення [6].

Тести можуть мати один або кілька варіантів відповідей, введення тексту і чисел, що випадають, списки. У налаштуваннях тестів є установка максимальних спроб відповідей, часу між спробами, вага тесту. При складанні тестів рекомендується кожне питання виводити в окремий компонент, для спрощення аналізу курсу в подальшому [6].

Відеосегменти курсу повинні тривати від 6 до 9 хвилин. Сегменти відео часто супроводжуються інтерактивними оцінками для рефлексії учнями. Маркетингове відео про курс має тривалість 30 секунд. Для створення інтерактивних відео в межах PowerPoint використовують інструмент Microsoft Mix [7].

У списку «Content» при виборі «Updates» додаються оновлення інформації на головній сторінці курсу (оголошення, терміни проведення оцінки, роздаткові матеріали). У тому ж меню «Content» при виборі "Files \& Uploads" вставляють посилання на файли. При завантаженні файлів існує обмеження на розмір файлу (10 мб). При додаванні підручника знадобиться файл PDF, для окремих підрозділів рекомендуються різні PDF-файли. У списку контенту можна додати користувацькі (поширені запитання, 
навчальний план, прогрес, навики і т.д.). Додані сторінки додаються в горизонтальному меню навігації по курсу [7].

Стандартна політика оцінки від 50\% прохідна, яка може градуюватися. Окремі підрозділи курсу можуть бути використані для оцінки у вікні налаштувань підрозділу. У налаштуваннях оцінювання визначаються типи завдань (тести, завдання, іспит) 3 визначенням їх частки з 100\%. За успішне виконання перевірочних тестових завдань всередині підрозділів може нараховуватися по 1 балу, за виконання завдань зведених тестів по розділах - по 2 бали, за виконання завдання, що вимагає самостійного написання матеріалу - 30 балів і т.п. У загальній оцінці за курс може також враховуватися активність того, хто навчається, бали можуть нараховуватися за участь у дискусіях [7]. Відображення оцінювання у студента з'являється на вкладці прогресу.

Члени команди розробки курсу в подальшому можуть модерувати навчання, дискусійні модератори можуть редагувати, видаляти повідомлення, залишати повідомлення, їх відгуки і коментарі відображаються при перегляді колірною індикацією.

Перед запуском курс проходить бетатестування. У чек-листі перевірки курсу повинні бути перевірка грамотності, роботи посилань, коректності та зрозумілості завдань, наявності передмов і коментарів. Може бути проведено експорт курсу файлом tar.gz. в списку інструментів $[6,10]$.

Рівень професіоналізму викладача безпосередньо впливає на рівень підготовки майбутнього фахівця, а тому успішне проходження курсів на відкритих платформах варто сприймати як підвищення кваліфікації для викладачів. Сертифікат про проходження курсу обсягом 3 і більше кредитів ECTS для довгострокового підвищення кваліфікації і до 2-х кредитів ECTS для короткострокового адміністрацією закладу може зараховуватися як підтвердження підвищення кваліфікації для науково-педагогічних працівників закладу освіти [12].

Працівниками нашої кафедри створено декілька онлайн-курсів на платформі Open edX «Енцефаліти», «Міастенія», «Шкали в неврології» та інші для курсів тематичного удосконалення лікарів, які активно використовуються при їх навчанні другий рік.

Висновки. Описано створення навчального онлайн-курсу на платформі Open edX, що відповідає сучасним уявленням про цілі навчання, детально викладені шляхи й методи організації розробки: розробка робочої програми (тематичний план), проект сценарію онлайн-курсу (розширений план курсу), сценарій онлайн-курсу (наповнення матеріалом проекту сценарію) і технічний перенос сценарію в Open edX Studio.

\section{References:}

1. Derezyuk AV. Deyaki aspekty suchasnoyi pedahohiky medychnoyi osvity [Some aspects of modern pedagogy of medical education]. Medychna osvita. 2015; 3:26-28. DOI http://dx.doi.org/10.11603/me. v0i3.4962. (in Ukrainian).
2. Kolesnyk YUM, Avramenko MO. Stratehiya vprovadzhennya kursiv za vyborom na bazi tekhnolohiyi onlayn-kursiv na platformi edX [A strategy for the introduction of elective courses based on online edX technology]. Suchasni pidkhody do vyshchoyi medychnoyi osvity $\mathrm{V}$ Ukrayini (z dystantsiynym pid"yednannyam VM(F)NZ Ukrayiny za dopomohoyu videokonferents-zv"yazku) : materialy XIV Vseukr. nauk.-prakt. konf. z mizhnar. uchastyu, prysvyachenoyi 60-richchyu TDMU (Ternopil', 18-19 trav. 2017 r.) : u 2 t. - Ternopil' : TDMU, 2017; 1:56-59. (in Ukrainian).

3. Kurinnyy AV, Volvach VV. Stvorennya ta rozrobka onlayn-kursu na platformi OPEN edX [Creating and developing an online course on the OPEN edX platform]. Medychna osvita. 2017; 2:37-40. DOI 10.11603/me.2414-5998.2017.2.7608. (in Ukrainian).

4. 7 uboynykh preymushchestv onlayn obuchenyya y MOOS nad tradytsyonnym obuchenyem [7 killing advantages of online training and MEP over traditional training] Available from: http://marketingbuzz.info/mooc. html\#ixzz4Yeyj1123. (in Russian).

5. Makarov OV, Borshch OA. Novi mozhlyvosti rozvytku system hibrydnoho navchannya $\mathrm{V}$ khimichniy tekhnolohiyi [New opportunities for the development of hybrid learning systems in chemical technology]. Komp"yuterno-informatsiyni tekhnolohiyi v bahatorivneviy vyshchiy osviti. 2018; 3:366-370. (in Ukrainian).

6. Rybalkyna DKH. Sozdanye uchebnoho kursa na platforme edX dlya smeshannoho obuchenyya [Creating an edX training course for blended learning]. Obrazovatel'nye tekhnolohyy y obshchestvo. 2016; 4:293-303.

7. Dyachenko O. Blended Learning na platforme Open edX: Perekhod ot tradytsyonnykh kursov v onlayn [Blended Learning on the Open edX Platform: Transition from Traditional Courses to Online] // Mat. ELForum, Kyev. 15.12.2016. P.20. Available from: URL: http://elf.etutorium.com/presentations/elforumdyachenko.pdf (in Russian).

8. Krapyvyna NYU, Halkyna LA. Metodycheskye ukazanyya dlya prepodavateley po podhotovke materyalov dlya sozdanyya onlayn-kursov, razmeshchaemykh na platforme otkrytoy onlaynakademyy Fynansovoho unyversyteta [Guidelines for teachers to prepare materials for the creation of online courses posted on the platform of the open online academy of the Financial University]. Fynansovyy unyversytet pry pravytel'stve RF, tsentr élektronnykh obrazovatel'nykh tekhnolohyy. Moskva, 2017. P.9. Available from: URL: http://www.fa.ru/org/div/ceot /Documents/oriop/createonline.pdf. (in Russian).

9. Arenkyna EA, Babanskaya OM. Putevodytel' po sozdanyyu onlayn-kursa [Online Course Design Guide] / Ynstytut dystantsyonnoho obrazovanyya. THU, Tomsk. 2015. P.16. Available from: URL: http://mooc.tsu.ru/wpcontent/uploads/2015/09/Pathfin der_MOOC_FINAL.pdf. (in Russian).

10. Bykov VYU, Kukharenko VM] Tekhnolohiya stvorennya dystantsiynoho kursu: navch. Posib 
[Technology of creating a distance course: tutorial. Tool]. Kyiv: Milenium; 2008. P.324. (in Ukrainian).

11. Donald S. Developing Instruction (Instructional Design) [Elektronnyy resurs]. Available from: http://www.nwlink.com/ donclark/hrd/learning/ development.html.

12. Zakonodavstvo Ukrayiny. (2013, Sichen` 24). Polozhennya pro pidvyshhennya kvalifikaciyi ta stazhuvannya pedagogichnyx i naukovopedagogichnyx pracivnykiv vyshhyx navchalnyx zakladiv. [Elektronnyj resurs]. Dostupno: https://zakon.rada.gov.ua/laws/show/z0488-13. Data zverennya: Sichen`24, 2013. in Ukrainian).

\section{УДК 37.091 .2 \\ ТЕХНИЧЕСКИЕ АСПЕКТЫ СОЗДАНИЯ ОНЛАЙН-КУРСОВ НА ПЛАТФОРМЕ ОРЕN $\mathrm{dX}$ ДЛЯ СМЕШАННОГО ОБУЧЕНИЯ}

\section{И.М. Пояснык}

\section{Ивано-Франковский национальный медииинский университет, кафедра неврологии и нейрохирургии, 2. Ивано-Франковск, Украина, ORCID ID: 0000-0002-6965-8631, e-mail:sof.3425@gmail.com}

Резюме. Новая концепция развития высшего медицинского образования в Украине, что ориентируется на мировые достижения подготовки врачей, предполагает коренные изменения качества образования. Онлайн-курсы имеют множество преимуществ по сравнению с традиционным обучением в университете. Анализ учебного плана и программ учебных дисциплин системы медицинского образования показал, что именно "онлайн-курсы", с позиций организации учебного процесса и дидактики преподавания, наиболее адаптированы к смешанной или дистанционной форме обучения.

Цель: создать и разработать онлайн-курс на платформе Open edX для мотивированных врачей, которым необходимы знания для профессионального развития, повышения квалификации или переквалификации.

Материали и методы. Платформа Open edX новая, с открытым исходным кодом, создает студентам и педагогам новые возможности творить и делиться, преподавать и изучать через исследование; адаптироваться к индивидуальным учебным нуждам. Она используется для дистанционного обучения в любое время и в любом месте, со свободным графиком обучения (в пределах периода прохождения курca).

Результаты. После утверждения рабочей программы члены команды приступают к разработке проекта сценария онлайн-курса. Следующий этап создание сценария онлайн-курса. Это завершенный проект, который начинает новый этап - техническое заполнение материалом онлайн-курса на платформе Open edX Studio, после которого происходит бетатестирования.
Выводы. Дистанционное обучение может быть таким же эффективным, как и традиционное. Привлечение в учебный процесс альтернативных методов обучения и знания их создания являются актуальным.

Ключевые слова: дистанционное образование, онлайн-курс, платформа Open edX.

\section{UDC 37.091.2 \\ TECHNICAL ASPECTS OF CREATING ONLINE COURSES ON THE OPEN EdX PLATFORM FOR BLENDED LEARNING}

\author{
I.M. Poiasnyk \\ Ivano-Frankivsk National Medical University, \\ Department neurology and neurosurgery, \\ Ivano-Frankivsk, Ukraine, \\ ORCID ID: 0000-0002-6965-8631, \\ e-mail:sof.3425@gmail.com
}

Abstract. The new concept of development of higher medical education in Ukraine, which is focused on the world achievements of physician training, envisages fundamental changes in the quality of education. The need to reform and improve it is one of the requirements on the path to European integration. Online courses have many advantages over a traditional university education. They are open, that is, anyone can subscribe to them. They are really massive: instead of lecturing to an audience of 100 students, the teacher gives it to millions of students around the world, the geography of students is limited only by the possibility of Internet access. In addition, the supply of material occurs through several channels, including the possibility of interactive interaction. Analysis of the curriculum and curricula of medical education disciplines showed that it is the "online courses", from the standpoint of the organization of the educational process and didactics of teaching, that are most adapted to blended or distance learning.

Objective: to create and develop an online course on the Open edX platform for motivated physicians who need knowledge for professional development, advanced training, or retraining.

Materials and methods. The Open edX platform is a new, open-source software that gives students and teachers new opportunities to create, share, teach, and learn through research; adapt to individual learning needs. They are used for distance learning anytime, anywhere, with a free training schedule (within the course period). This concept is called active learning.

Results. Once the work program is approved, the team members begin to develop a draft online course script. The next step is to create an online course script. This is a completed project that begins a new phase - the technical filling of the online course material for the Open edX Studio platform. Members of the course development team can moderate the training, discussion moderators can edit, delete messages, leave messages, their feedback, and comments are displayed when viewed 
in color. Before starting the course is beta tested. The checklist of the course should include a check of literacy, references, correctness and clarity of tasks, the presence of prefaces, and comments. The overall assessment of the course may also take into account the activity of the student, points may be credited for participating in discussions. The student's assessment display appears on the progress tab. The level of professionalism of the academic directly affects the level of training of the future specialist, and therefore the successful completion of courses on open platforms should be perceived as professional development for scientists. Certificate of completion of a course of 3 or more ECTS credits for long-term training and up to 2 ECTS credits for short-term administration of the institution may be credited as proof of advanced training for research and teaching staff of the educational institution.

Conclusions. Distance learning can be as effective as traditional. Massively open online courses on the Internet are actively displacing other forms of distance learning. The involvement of alternative teaching methods and knowledge of their creation are relevant. Intercultural learning environments provide an opportunity to share experiences, solve problems together, forming relationships with colleagues around the world.

Keywords: distance education, online course, Open edX platform.

Стаття надійшла в редакцію 05.05.2020 p. 